\title{
Activity, startle magnitude, and prolonged food and water deprivation: Two further failures to duplicate
}

\author{
D. CHRIS ANDERSON, CHARLES R. CROWELL, and LISA SIROKY \\ University of Notre Dame, Notre Dame, Indiana
}

\begin{abstract}
Studies from one laboratory have shown deprivation-induced attenuation of startle response magnitudes, but another laboratory has reported failures to show any relationship between these variables. In an attempt to locate possible procedural contributions to this discrepancy in outcomes, our Experiment 1 involved 20 massed startle-stimulus presentations (30-sec ISI) to rats that had gone either $43 \mathrm{~h}$ or $1 \mathrm{~h}$ since eating ( $80 \%$ body weights equated for groups). Experiment 2 entailed spaced presentations (four trials per five bidaily sessions, 20-min ISI) to rats that had gone either $43 \mathrm{~h}$ or $1 \mathrm{~h}$ since drinking ( $80 \%$ weights also equated). Activity prior to, during, and after startle presentations also was recorded. Although group startle magnitudes differed on some trial blocks of both experiments, these differences were not systematically related to either of the deprivation conditions. Mean activity level was sensitive to startle-stimulus presentations, and showed systematic trial-block rates of decline for periods prior to, during, and following startle presentations that were identical for all groups.
\end{abstract}

In a frequently cited but unpublished study, Meryman (1952) reported that a stimulus previously paired respectively with electric shock (a fear CS) and with prolonged food deprivation could intensify startle reactions to an intense, punctate acoustic stimulus. He further showed that even larger startle magnitudes resulted from the combined presence of both stimuli. Anderson, Crowell, and Brown (1985) more recently published a detailed exposition of Meryman's (1952) study and duplicated its essential features. They similarly found lower startle magnitudes to a fear CS alone than to a fear CS presented in combination with food deprivation. However, in contrast to Meryman, they reported that food deprivation alone was ineffective in facilitating startle magnitude.

Anderson et al. (1985) explained the latter disparity by proposing that augmented startle magnitude was occasioned exclusively by the fear CS in these studies, and that satiation may have served to attenuate fear rather than that deprivation intensified startle. They further deduced that Meryman's alleged nonfearful groups probably were modestly fearful but, because of a procedural modification, their groups were not. Because of the postulations that satiation in the absence of fear, along with deprivation per se, should exert null influence on startle magnitude, we then applied Anderson et al.'s (1985) satiation, fear-attenuation proposal to explain the startle differences associated with these two studies.

Unfortunately, the latter conceptualization does not concur with reports that food or water deprivation may at-

Please send reprint requests to: D. C. Anderson, Department of Psychology, 112 Haggar Hall, University of Notre Dame, Notre Dame, IN 46556 . tenuate startle magnitudes (Fechter \& Ison, 1972; Ison \& Krauter, 1975). However, Anderson, Sergio, and Ewing (1982) suggested that procedural variances might account for the difference between the deprivation, startleattenuation findings of Ison and colleagues and the null outcome of Anderson et al. (1985). They noted, for example, that Ison and colleagues gave many more startles per session and more overall than either Meryman or Anderson, Crowell, and Brown did; that deprivation regimens often differed; and that Ison and colleagues usually employed within-subjects rather than between-groups procedures. Anderson et al. (1982) evaluated one of these variances-different deprivation regimens-but failed to show that this manipulation reliably affected startle magnitudes. The present studies represent additional attempts to reconcile these disparate outcomes through procedural evaluations.

It can be inferred from Ison and Krauter's (1975) research that the time intervals (ISIs) separating presentations of their eliciting stimulus were relatively short (25$35 \mathrm{sec}$ ), as contrasted with the approximately $20+\mathrm{min}$ ISI spacings of Meryman and of Anderson et al. (1982, 1985). Although the stimulus spacings of Ison may exceed values that yield "stimulus-prepulse" startleattenuation effects (see Ison \& Hammond, 1971), they nonetheless qualify as "massed" presentations. One consequence of massed stimulus presentations is that they can produce markedly greater habituation of startle frequency than do spaced presentations (Davis, 1974; Davis \& Wagner, 1969), the latter thereby being of possible importance to the deprivation, startle-attenuation outcome of Ison and colleagues. Our Experiment 1 represented a preliminary attempt to evaluate whether stimulus mass- 
ing was important by simply substituting within the basic procedures of Anderson and colleagues $(1982 ; 1985)$ a massed startle-stimulus for a spaced startle-stimulus presentation sequence.

In addition, there has been considerable controversy regarding possible relationships between prestartle movement patterns and startle magnitude. Anderson, Johnson, and Kempton (1969a; 1969b), Brown, Kalish, and Farber (1951), Davis and Astrachan (1978), Ison and Krauter (1975), and Kurtz and Seigel (1966) variously have argued both for and against a possible inverse relationship between movement and startle. We employed a motion detector in the present study to continously monitor activity in second $X$ second intervals prior to, during, and following startle elicitations.

\section{EXPERIMENT 1}

\section{Method}

Subjects. We used 12 male, albino, 134 to 154 day-old SpragueDawley rats, purchased from King Animal Laboratories. Each rat was singly caged, was given ad lib access to water throughout the study, and was weighed and handled daily. Ten days prior to testing, all rats were placed on a 44 -h food deprivation cycle in order to achieve $80 \%$ of their predeprivation body weights (maintained $\pm 2 \%$ during the study). Deprivation cycles were temporally staggered so that half of the rats were given food 3-4 h prior to the other half. Startle testing thus could be conducted at the same time of day for all subjects.

Apparatus. The apparatus consisted of a startle test chamber (modeled after Hoffman \& Fleshler, 1964); a sound-deadened, fan-ventilated and light-controlled enclosure; a 10.3-cm-diam Quam speaker; and a Grason-Stadler (Model 901B) white-noise generator. Ancillary devices included an oscilloscope to monitor the voltage output of the startletransduction system, a General-Radio sound intensity calibration meter, and a computer located outside the laboratory. The computer digitized the analogue voltage output of the startle transducer, detected the peak reading, and recorded and stored (using a disk system) the resulting values in 1-mV units. Startle-stimulus duration was $20 \mathrm{msec}$, and peak intensity was about $110 \mathrm{~dB}, \mathrm{~A}$-weighted measurement. All other relevant details regarding the apparatus are given in Anderson et al. (1982).

Ultrasonic transmitting and receiving transducers were located to the side $(27 \mathrm{~cm})$ and oriented to the long axis $(3 \mathrm{~cm}$ from the chamber ends) of the chamber. These devices were connected outside the enclosure to an ultrasonic motion detector device (circuitry modified after the $\mathrm{Al}$ ton Model-5 Motion Detector) which, in turn, was connected to the lab computer. Calibration for the motion detector was accomplished by inserting into the chamber a 45-rpm "paddle." Sensitivity of the motion detector was set so that gross bodily movements would be readily detected but that more miniscule actions, such as modest head-turning, would not be detected.

Procedure. The study was run in two identical, sequentially conducted replications of six rats each, the second session beginning immediately upon completion of the first. Within each replication, rats were assigned to one of two groups using a randomized-blocks procedure that equated for body weight.

Subjects were adapted to the startle chamber for 1-2 min, and then given 20 consecutive startle-stimulus presentations spaced $30 \mathrm{sec}$ apart. The presentations were given approximately $43 \mathrm{~h}$ after the last feeding (deprived) for one group and about $1 \mathrm{~h}$ following feeding (satiated) for the other group.

We recorded peak readings in $\mathrm{mV}$ (all occurred within $500 \mathrm{msec}$ of startle-stimulus onset); reflecting startle magnitudes; and second $\times$ second numbers of movements for the 20 -sec period preceding, the 1 -sec period during, and 4-sec period following each startle trial. Because the ultrasonic motion detector was on throughout the entire testing procedure for each rat, movement data simply were sampled as specified. The ultrasonic tone probably served, along with the ventilation fan, as background masking stimulus that, considering the findings of Ison and Hammond (1971), likely exerted a modest but nondifferential attenuating influence on startle magnitude.

\section{Results}

Startle magnitude. Mean startle magnitudes, expressed in $\mathrm{mV}$ and averaged over blocks of four stimulus presentations, are shown in Figure 1 for each of the two deprivation conditions. (Replication effects were not reliable and are not mentioned further.) The blocks for both groups show declines in startle, and rats in the deprived condition are associated with arithmetically larger magnitudes at all points than satiated rats.

When subjected to a mixed-model $2 \times 5 \times 4$ (groups $\times$ blocks $\times$ trials) factorial ANOVA, the only reliable $F$ value was for blocks $[F(4,40)=3.6, p<.025]$. Although the $F$ value for the groups effect was not reliable $(p<.15)$, some of the differences between groups in Figure 1 appear arithmetically larger for some blocks than for others. Accordingly, a posteriori followup tests, corrected for inflated alpha error rates, were performed for each block. The respective $\mathrm{t}$ values (all $\mathrm{df}=40$ ) for Blocks 1-5 were .96 (Block 1), 2.4 (Block 2), 2.9 (Block 3), 2.4 (Block 4), and 1.7 (Block 5). Those tests for the intermediate three blocks thus proved marginally reliable.

Movement. Several analyses of these complex data were required to extract all possible relevant outcomes. One analysis was for movement preceding startle exposures, and involved a $2 \times 5 \times 4 \times 20$ (groups $\times$ trial blocks $\times$ trials $\times$ seconds per trial) ANOVA. The only reliable effect was for the marked and approximately equivalent blockwise decline for both groups in mean movement $[F(4,40)=20.1, p<.01]$.

A second analysis involved respective movement in the 1-sec time frames immediately preceding and during startle-stimulus exposure. The reliable findings from this analysis were, again, that there was a general decline for

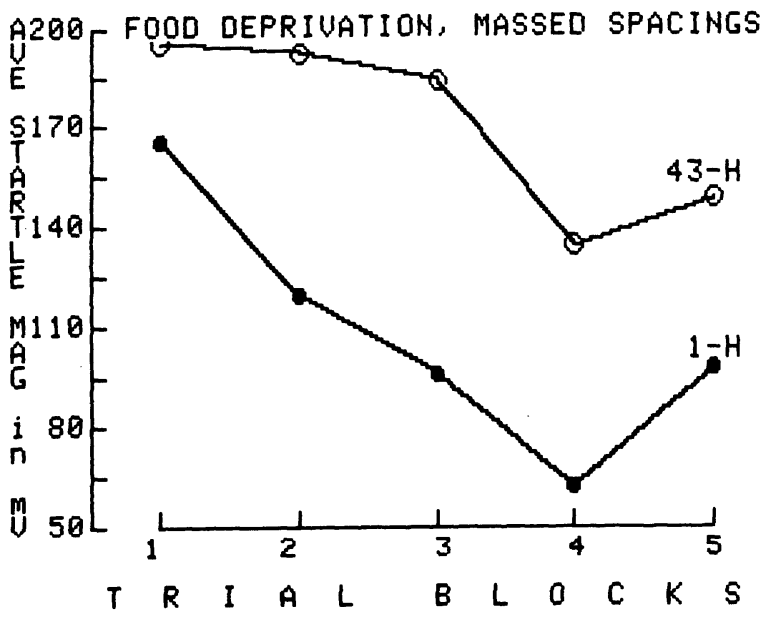

Figure 1. Mean startle amplitudes (in $\mathrm{mV}$ ) for five blocks of four startle test trials (massed presentations) for each of two groups. Group 43-h was tested $43 \mathrm{~h}$ after feeding while Group 1-h was tested $1 \mathrm{~h}$ following consummation of its bidaily food ration. 
both groups in movement across trial blocks $[\mathrm{F}(4,40)=$ $14.6, \mathrm{p}<.01$ ] and a marked increase for both groups in movement from the pre- to the 1 -sec startle time frame $[\mathrm{F}(1,10)=220.0, \mathrm{p}<.01]$. A third analysis involved the exposure and first 1-sec poststartle time frames. Mean movements per second during and immediately following startle were 1.77 and .08 , respectively, for the deprived group and were 1.74 and .03 for the satiated group. Only the $F$ value for time frames was reliable $[F(1,10)=396.5, p<.01]$. A final evaluation involved the 4-sec poststartle time frames, and no reliable effects emerged from this analysis.

Startle-movement correlations. Movement during the 1 -sec period immediately preceding startle and the startle magnitude for the 20 trials of each subject were correlated. Each of these coefficients was evaluated for statistical reliability. In addition, they were collectively subjected, as independent scores, to a t-test to determine if respective grouped sets tenably belonged to the same parent population of coefficients. Finally, 20-trial movement and magnitude averages were calculated for each rat from these data, supplying 12 independent pairs of covariates that provided the basis for an overall acrosssubjects coefficient.

Because movement almost always subsided to zero values following exposure to the first startle stimulus, all within-rat coefficients approximated zero (all ps $<.20$ ).

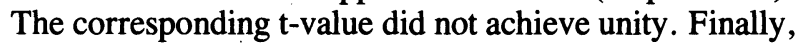
the across-subjects coefficient $[\mathrm{r}(10)=-.09]$ was not reliable.

\section{Discussion}

Basically, the present study constituted another failure to duplicate the apparently robust and arithmetically marked findings by Fechter and Ison (1972) and Ison and Krauter (1975) of attenuated startle induced by food deprivation. Although our study had fewer startle trials than these previous studies, our 20 trials equalled the numbers used by Meryman (1952) and for the two reports of Anderson et al. $(1982,1985)$ and otherwise were introduced in a manner similar to that reported by Ison and colleagues (all in a single session using a closely massed interstimulus interval of $30 \mathrm{sec}$ ). Moreover, we tightly regulated both deprivation regimen and body weights, and our data suggest that habituation was complete well before the last block of startle presentations (as likely was the case in Ison's studies). Indeed, those differences in startle magnitude traceable to food deprivation that did show up favored the findings of Meryman (1952) and Mellgren (1969) of hunger-related startle intensification.

In continuing the search for possible critical methodological ingredients that might shed information on these outcomes, we made a procedural change for Experiment 2. We noted in this connection that Ison and colleagues showed attenuated startle for water as well as food privation. We thus substituted a water-deprivation regimen for the fooddeprivation regimen of Experiment 1. Because stimulus spacing proved not to be an important factor in the deprivation variable in our series of between-groups experiments (cf. Experiment 1 with Anderson et al., 1982), we employed a spaced startle-presentation procedure similar to our previous efforts.

\section{EXPERIMENT 2}

\section{Method}

Subjects, apparatus, and procedure. Fourteen rats of the same age, sex, and supplier as Experiment 1 were used. All were treated the same as in the preceding experiment except that, five days after delivery, each was placed on a water-deprivation cycle analogous to the food-privation procedure of Experiment 1 . Once $80 \%$ body weights were achieved, water (freshly constituted with $4 \mathrm{ml}$ ViDalin vitamin supplement, homogenized form) was regulated to maintain these levels throughout the study on a 44-h deprivation schedule. All rats were given ad lib access to food throughout the water-deprivation period. Two groups of seven rats each then were formed and equated for body weights (randomized-blocks assignment). The apparatus was the same as in Experiment 1 .

Startle testing occurred every other day for a total of five sessions of four trials each for one group $43 \mathrm{~h}$ after drinking (deprived), and, for the other, $1 \mathrm{~h}$ after drinking (sated). Testing entailed carrying each rat from the colony to the test room, presenting the startle stimulus about $30 \mathrm{sec}$ after placing the rat into the chamber, and then returning the rat to its home cage. This procedure was repeated through completion of the fourth test trial. The testing procedure additionally equated groups for time of day, handling, testing order, session duration, experimenter contact, and so forth through a combination of random assignment and quasi-counterbalancing procedures.

\section{Results}

Startle magnitude. Mean startle magnitude for the 43-h and 1-h water-deprived groups, expressed in $\mathrm{mV}$ peak readings as four-trial block averages, are shown in Figure 2. As shown, the pattern of mean startle magnitudes differed by group. Mean startle magnitudes for the sated group were arithmetically larger for the initial three blocks and then lower than for the thirsty subjects for the two terminal trial blocks. These different patterns were reflected in a reliable groups $\times$ blocks $F$-value $[F(4,48)$ $=2.62, p<.05]$, resulting from application of appropriate mixed-model ANOVA to these data. Followup paired comparisons for each of trial blocks 2, 3 and 4, adjusted for inflated alpha error rates, resulted in reliable t-values (all ps < .01). However, two of these three differences entailed thirst-attenuated and one involved thirstaugmented startle magnitudes.

Movement. As with Experiment 1, the only conspicuous feature of the 20-sec prestartle-period movement data was the equivalent and uniform blockwise decline in activity for both groups. This blockwise decline in move-

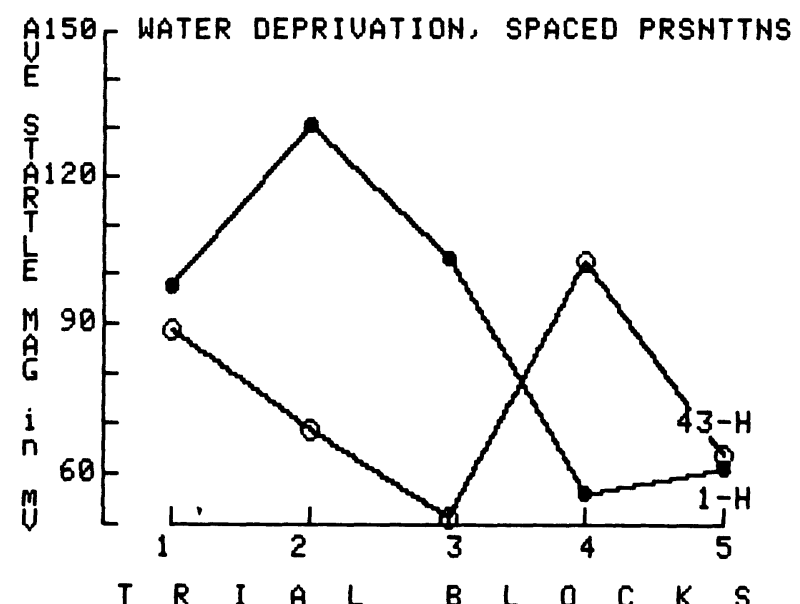

Figure 2. Mean startle amplitudes (in $\mathrm{mV}$ ) for five blocks of four startle test trials (spaced presentations, four trials per bidaily sessions, 20 min ISI) for each of two groups. The group legend is the same as for Figure 1. 
ment also was apparent both during the 1-sec startle interval and for the 4-sec poststartle time. However, in contrast to pre- and during-startle movement levels, overall activity level varied by deprivation condition over the 4-sec, poststartle period. Water-deprived rats moved reliably less during this period than did sated ones $[F(1,12)$ $=4.51, \mathrm{p}<.05]$. As with Experiment 1 , activity level again markedly was influenced by the startle stimulus, being less than .2 mean movements for the 1 -sec pre- and poststartle periods and 1.52 and 1.67 mean movements for the thirsty and sated groups, respectively, during the startle interval.

We performed correlations (both within and between subjects) between startle magnitude and the movement immediately preceding startle. Again, all coefficients were near zero, and were not reliable.

\section{DISCUSSION}

Revelation of a consistent overall effect on startle magnitude due to tissue deprivation again proved to be an elusive phenomenon in these experiments. Although marginally reliable differences occurred on some trial blocks, these were not systematically ordered either within or across studies with regard to direction of effects. Moreover, taken with the preceding studies of Anderson and colleagues (1982, 1985), such null outcomes have occurred in spite of wide variations in interstartle intervals, in deprivation type and regimen, and in apparatuses. In connection with the latter, the startle apparatus of Anderson et al. (1985) was quite different than that used for the present studies. The current apparatus was carefully fashioned after Hoffman and Fleshler (1964) and was apparently used also by Ison and colleagues. Similar apparatuses presumably have been employed in studies associated both with striking and with essentially null startle-deprivation effects. Moreover, startle magnitude as transduced by the present apparatus was sensitive to trialblockwise, habituation-like effects (see Thompson \& Spencer, 1966). This raises the further concern of why the present equipment was sensitive to the influence(s) of one variable (repetitious stimulus presentations) but not to another (deprivation). Also of possible relevance here was that the magnitude data parallelled those of a second, different dependent variable (movement). Both provided clear evidence of startlestimulus effectiveness and of habituation, but not of effects attributable to tissue privation. These considerations seemingly suggest that a continued search for current discrepancies in deprivation-startle outcomes likely should proceed in directions other than those associated with concerns over apparatus sensitivity.

While not questioning the authenticity of the robust and consistent deprivation, startle-attenuation effects reported by Ison and colleagues, the equally systematic lack of these effects across the present and prior studies in our laboratory also are factual and internally consistent. We feel almost apologetic for not having a resolution for this apparent contradiction, although one may emerge as we evaluate certain of the above variables in a completely within-subjects procedure (such as Ison often has used). In the meantime, we can only restate (cf. Anderson et al., 1982) that, whatever the ultimate resolution, the phenomenon under scrutiny appears highly dependent upon special and as yet seemingly undiscovered factors. Taken as a whole, this suggests quite fragile and limited external validity for such.

A final point of interest in the present studies was the null effect of protracted and marked deprivation on general activity. While repeti- tious exposure to the startle stimulus exerted potent influences on movement, no other variables did across the present two studies. (A singular exception here among the large number of essentially null results was attenuated poststartle activity for thirsty versus sated rats in Experiment 2. It thus is difficult to know what significance to place on this result at present.) These generally null outcomes at least are consistent with a portion of the extant deprivation, general-activity literature (Baumeister, Hawkins, \& Cromwell, 1964).

\section{REFERENCES}

Anderson, D. C., Crowell, C. R., \& Brown, J. S. (1985). Startle potentiation and heartrate as affected by hunger and fear. Psychological Reports, 56, 95-106.

ANDERson, D. C., Johnson, D., \& Kempton, H. (1969a). Second order fear conditioning as revealed through augmentation of a startle response: Part I. Psychonomic Science, 16, 5-7.

Anderson, D. C., Johnson, D., \& KemPTon, H. (1969b). Second order fear conditioning as revealed through augmentation of a startle response: Part II. Psychonomic Science, 16, 7-9.

Anderson, D. C., Sergio, J., \& EwING, M. (1982). Food deprivation and startle magnitude: Inhibition, potentiation, or neither? Bulletin of the Psychonomic Society, 19, 165-168.

Baumeister, A., Hawkins, W. F., \& Cromwell, R. L. (1964). Need states and activity level. Psychological Bulletin, 61, 438-453.

Brown, J. S., Kalish, H. I., \& FARBER, I. E. (1951). Conditioned fear as revealed by magnitude of startle response to an auditory stimulus. Journal of Experimental Psychology, 41, 317-328.

DAVIs, M. J. (1974). Signal-to-noise ratio as a predictor of startle amplitude and habituation in the rat. Journal of Comparative \& Physiological Psychology, 86, 812-825.

Davis, M., \& Astrachan, D. I. (1978). Conditioned fear and startle magnitude: Effects of different footshock or backshock intensities used in training. Journal of Experimental Psychology: Animal Behavior Processes, 4, 95-103.

DAVIS, M., \& WAGNER, A. R. (1969). Habituation of startle response under incremental sequence of stimulus intensities. Journal of Comparative \& Physiological Psychology, 67, 480-492.

Fechter, L. D., \& Ison, J. R. (1972). The inhibition of the acoustic startle reaction in rats by food and water deprivation. Learning \& Motivation, 3, 109-124.

HoffMAN, H. S., \& FleShleR, M. (1964) An apparatus for the measurement of the startle-response in the rat. American Journal of Psychology, 77, 307-308.

Ison, J. R., \& HAMMOND, G. R. (1971). Modification of the startle reflex in the rat by changes in the auditory and visual environments. Journal of Comparative \& Physiological Psychology, 75, 435-452.

IsON, J. R., \& KRAUTER, E. E. (1975). Acoustic startle reflexes in the rat during consummatory behavior. Journal of Comparative \& Physiological Psychology, 89, 39-49.

KurTz, K. H., \& SiEgEL, A. (1966). Conditioned fear and magnitude of startle response: A replication and extension. Journal of Comparative \& Physiological Psychology, 62, 8-14.

MellgRen, R. L. (1969). Magnitude of the startle response and drive level. Psychological Reports, 25, 187-193.

MERYMAN, J. J. (1952). The magnitude of startle response as a function of hunger and fear. Unpublished master's thesis, University of Iowa, Iowa City.

Thompson, R. F., \& SPEnCER, W. A. (1966). Habituation: A model phenomenon for the study of neuronal substrates of behavior. Psychological Review, 73, 16-43.

(Manuscript received for publication February 25, 1985.) 